\title{
A SUCESSÃO DE GERAÇÕES: fechando um ciclo da vida (Notas de homenagem a Guaraci Adeodato) ${ }^{1}$
}

\author{
Anete B. L. Ivo*
}

Homenagear Guaraci Adeodato Alves de Souza, minha amiga e colega de tantos anos, sob o impacto de seu desaparecimento do nosso convívio, em 10 de dezembro de 2014, é extremamente difícil e doloroso, porque parece fechar um ciclo da história de vida afetiva e institucional, lamentavelmente interrompido. Acompanhando o que diz sabiamente Mirabeau (Souza), seu companheiro de mais de quatro décadas, e suas filhas amadas, Bia (Beatriz) e Nana (Mariana), "nós estamos aprendendo a conviver com essa ausência e essa saudade". E esse é um aprendizado que se estende a todos nós, seus amigos.

Guara era exuberante nas ideias, incisiva na palavra, comprometida com o trabalho acadêmico sério e rigoroso, guerreira na defesa institucional, generosa e solidária com o que julgava justo. Uma genuína "filha de Ogum", impulsiva, enérgica, combativa e ousada, mas também proparoxítona no entusiasmo e nos

* Doutora em Sociologia. Professora aposentada da UFBA, com vinculação ao Programa de Pós-Graduação em Ciências Sociais e ao Centro de Estudos e Pesquisa em Humanidades (CRH) da Faculdade de Filosofia e Ciências Humanas. Pesquisadora do CNPq. Professora do Programa de Políticas Sociais e Cidadania da Universidade Católica de Salvador. Estrada de São Lázaro, 197- Federação. Cep: 40.210-730. Salvador - Bahia - Brasil. anetivo@hotmail.com

${ }^{1}$ Agradeço os comentários e sugestões da colega Tânia Franco, que qualificaram melhor este texto. afetos. A força dessa personalidade me deixou em dúvidas se eu conseguiria, nessas pequenas notas, dar autenticidade à sua 'vida vivida', sem incorrer em imprecisões de sentido quanto às suas experiências, as quais, apesar de compartilhadas por mim e outros colegas, são singulares e genuínas. Cabe, portanto, a reserva necessária e desculpas antecipadas por eventuais erros, esclarecendo que este texto é apenas uma seleção de pontos de vista meus, que não necessariamente seriam traduzidos por ela, ou outros colegas, dessa mesma forma. Apesar da dificuldade em encontrar o fio condutor deste texto, pelas circunstâncias e emoção da despedida, sinto-me honrada com o convite da revista para escrevê-lo. Além da justa homenagem a uma das pesquisadoras fundadoras do Centro de Recursos Humanos - CRH (hoje Centro de Estudos e Pesquisas em Humanidades), e uma das mais veementes defensoras de sua institucionalização como centro de pesquisas interdisciplinares em Ciências Sociais, Guaraci é autora de uma produção acadêmica relevante e criativa no campo dos estudos sociodemográficos, com reconhecimento nacional, desde os anos setenta, período em que era extremamente difícil a pesquisadores, fora do eixo Rio e São Paulo, publicarem. Como 
afirma a Nota de Falecimento da Associação Brasileira de Estudos Populacionais (ABEP), redigida por Elizabeth Bilac, uma grande estimuladora do seu trabalho e parceira de alguns projetos, Guaraci foi "[...] uma das pioneiras que tornou possível a constituição da Demografia como área disciplinar em nosso país".

Guaraci Adeodato Alves de Souza ingressou na Universidade Federal da Bahia (UFBA) como técnica-pesquisadora contratada por convênio para compor a equipe inicial do Programa de Recursos Humanos da Universidade Federal da Bahia, em 1969, que antecedeu a institucionalização do Centro de Recursos Humanos, como órgão suplementar de pesquisas em ciências sociais da UFBA, em 1973. Realizou concurso para Auxiliar de Ensino do departamento de Sociologia em 1973, e para professor Assistente em 1980, ambos para a disciplina Demografia. Desde então, lutou para garantir o lugar dessa disciplina e o seu próprio - como professora da disciplina -, na estrutura departamental da Universidade, não sem dificuldades, pela inexistência de curso regular de graduação em Demografia, o que a colocava sempre em situação de excepcionalidade, ainda que compreendida a justeza de suas demandas pelos colegas. Mesmo assim, conseguiu colaborar para a formação de novas gerações de especialistas nessa área, na Bahia e no Nordeste, sobretudo a partir da oferta de + cursos de curta duração, ministrados em par¿্. ceria com órgãos públicos de planejamento e ¿ com outros centros nacionais.

Com uma formação multidisciplinar, seus trabalhos exploraram, inicialmente, a interface da dinâmica demográfica com o processo de desenvolvimento urbano e regional. Diplo¿. mou-se em Serviço Social pela Universidade ^ Católica do Salvador em 1965. Logo após, rea\& lizou dois cursos de especialização, o primeiลิ ro, Formation en Dévellopement (1968), no Ins$\therefore$ titut International de Recherche et Formation en vue du Developpement (IRFED), em Paris; e o segundo, uma Especialização em Dinâmica Populacional (1969), na USP, ambos decisivos para sua reorientação aos estudos demográficos, na interface entre os processos de "Urbanização e Desenvolvimento”. Em 1976 defendeu a dissertação Migração e Subemprego em Salvador no mestrado de Economia da UFBA, que obteve reconhecimento nacional com o Prêmio de Melhor Dissertação de Mestrado concedido pela Associação Nacional de Centros de PósGraduação em Economia (ANPEC), em 1977. A monografia foi publicada em Salvador, pela CPE-Seplantec, em 1978.

Tendo convivido, no CEBRAP (São Paulo), com ilustres intelectuais brasileiros ao final da década de 60 e início da década de 70, ela acompanhou um conjunto de reflexões que buscava decifrar a natureza do capitalismo num país periférico. Da experiência com a equipe do CEBRAP, num convênio com o CRH para a realização da pesquisa "Força de Trabalho e Desenvolvimento", em 1971, resultou o livro Bahia de Todos os Pobres, organizado por ela e Vilmar Faria, numa coedição da Editora Vozes com o CEBRAP (Caderno CEBRAP $n^{\circ}$ 34), publicado em 1980. Esse livro tornou-se referência nos estudos sobre desenvolvimento, discutindo as "características gerais do desenvolvimento da área metropolitana de Salvador, sua dinâmica populacional, sua estrutura do emprego e de renda, examinando a situação dos mais pobres: os trabalhadores autônomos, a população marginalizada, as mulheres trabalhadores", conforme texto da contracapa do livro. Nele colaboraram: Francisco de Oliveira, autor do prefácio e, nos capítulos, além dos próprios organizadores, Paul Singer; Inaiá Carvalho (em coautoria com Guaraci Adeodato A. de Souza); Reginaldo Prandi; Elizabeth Jelin e Ângela Ramalho Viana.

A partir de meados da década de oitenta, Guaraci inicia uma incursão metodológica na crítica à Demografia Formal, especialmente à noção de Transição Demográfica, explorando nexos explicativos entre as tendências quantitativas da fecundidade com as mudanças qualitativas dos padrões de procriação e reprodução das famílias, na Bahia (1986-1996). Segundo a própria autora, esses estudos buscavam:

[...] uma formulação teórica sobre a reprodução demográfica que desse conta de uma adequada interpretação desse processo enquanto processo social e histórico, tanto nos seus movimentos sincrônicos, quanto diacrônicos. No plano empírico voltava-se, 
sobretudo, para reconstruir as experiências históricas de mudança na fecundidade e nos padrões de procriação, associadas a alterações estruturais em outras dimensões da sucessão das gerações. (cf. Linhas de pesquisa 1986-1996, Curriculum Vitae, CNPq)

Essas preocupações coincidem com um vigoroso processo de renovação institucional e acadêmica no então Centro de Recursos Humanos, iniciado na formulação das linhas de pesquisa, em 1981. Ainda que o projeto principal do Centro, naquela época, fosse eminentemente quantitativo, voltado para recompor as tendências da população, emprego e educação da força de trabalho na Bahia, a sua realização convive com um instigante e rico circuito de novas ideias, teses e autores, propiciado pelas inflexões paradigmáticas das ciências sociais, mas também pelo retorno de vários pesquisadores dos doutorados em outros países, pelos intercâmbios internacionais e a acolhida de muitos pesquisadores estrangeiros, no CRH, especialmente a partir de 1986. Pensava-se sobre novos desafios metodológicos e conceituais da pesquisa, destacando as relações entre produção e reprodução; processo de trabalho e saúde; a natureza das classes, suas representações e identidades; os novos movimentos sociais; as novas divisões do trabalho com ênfase na divisão sexual do trabalho; a diferenciação política no contexto da democratização; as relações entre as unidades empíricas e disciplinares entre o rural e o urbano; estudos qualitativos na área de educação; as mediações entre estrutura e sujeitos; e a importância de técnicas qualitativas de recomposição de trajetórias dos sujeitos, entre outras questões.

Os vários seminários internos realizados no CRH constituíam experiências únicas, onde a discussão das pesquisas de cada um(a) funcionava como um verdadeiro laboratório de ideias, formulação de hipóteses e definição de recortes, que se constituíam em fontes heurísticas para a construção de novos objetos de pesquisa, criando, gradativamente, a nossa identidade institucional de pesquisa. O que chama a atenção hoje é como aquele pequeno grupo de jovens pesquisadores tinha disposição e disciplina intelectual para discutir proposições de pesquisa, algumas "ambiciosas”, numa espécie de socia- lização mútua, mesmo enfrentando, às vezes, a impropriedade de algumas críticas, pela juventude da equipe, mas que nos fazia, ao mesmo tempo, aprendizes e lideranças de pesquisa, e formadores, também, de novas gerações. Em que pesem as divergências metodológicas e a diferenciação de campos de pesquisas, essa experiência foi extremamente fecunda, no sentido de construir uma formação da pesquisa coletiva de um centro acadêmico.

No período do seu doutorado em Ciências Sociais, realizado na Universidade Estadual de Campinas - UNICAMP (1986-1996), Guaraci inicia um processo particularmente criativo de crítica metodológica aos limites da Demografia Formal. Numa interpretação a posteriori, ouso afirmar que sua crítica buscava desnaturalizar a abstração dos constructos quantitativos da Demografia, associando a "produção dos números e indicadores demográficos", tanto aos determinantes da reprodução biológica e sociocultural, quanto às práticas de procriação e constituição das proles dos membros das famílias, como elementos intrínsecos dos padrões de fecundidade e dos ciclos reprodutivos das famílias e das gerações. Essa incursão, me parece, sustentavase em grande parte na noção de reprodução de Pierre Bourdieu.

A sua crítica pretendia ultrapassar, também, equívocos de algumas concepções da divisão de trabalho entre disciplinas, que dissociava o momento da "descrição" estatística (demográfica) do esforço explicativo (da Sociologia). A autora solucionava essa inadequada justaposição de campos disciplinares pela noção de "totalidade", numa síntese complexa de movimentos diacrônicos e sincrônicos de análise da realidade, como sugere o subtítulo da sua tese: o reencontro com a totalidade esquecida. Essas proposições foram sistematicamente publicadas em vários artigos escritos de 1987 até a década de 2000, mas encontram a sua formulação mais completa e amadurecida na tese Sucessão das gerações na Bahia: reencontro de uma totalidade esquecida, defendida em 1996, na UNICAMP, sob a orientação de Maria Coleta Oliveira.

Em depoimento, Maria Coleta esclarece que "[...] a formulação teórica de Guaraci 
buscava reduzir, senão eliminar o fosso, entre as formulações quantitativas e qualitativas. $\mathrm{O}$ fosso e as contradições entre as relações de quantidades e entre qualidades". E, continua: "Este raciocínio tem origem no meu, mas eu não domino Lotka nem propus o que Guara propôs! Ela sempre dizia que ela seguiu os meus passos adiante onde eu não havia chegado! Foi uma fase de fecundidade recíproca! A tese de Guara merece ser publicada em livro, inteira!", diz Coleta. A respeito do impacto dessas proposições na comunidade dos demógrafos, Maria Coleta complementa: “[...] o caráter inovador de suas formulações não provocou - como seria de se esperar - reações de unanimidade. Mas o tempo é senhor de todas as coisas, e suas formulações encontrariam paralelo na demografia contemporânea mais avançada! Tarda, mas não falha!”

No centro dessas preocupações, concluo, encontram-se inovadoras proposições sobre a relação socialmente construída entre fecundidade, procriação, família, reprodução biológica e social, sintetizadas na noção de "sucessão de gerações", originalmente formulada por Lotka, como também esclarece Coleta, e retomada por Guaraci em sua tese e em muitos dos seus artigos, cursos e exposições.

Além dessa criativa produção acadêmica, Guaraci assumiu com vigor a defesa do Centro de Recursos Humanos, em vários períodos * de incerteza institucional, especialmente na S primeira década, razão pela qual o seu nome e ه o do Centro de Recursos Humanos são indissociáveis. Atendendo às finalidades regimentais do CRH, e seguindo a preocupação constante de externalização dos resultados da pesquisa universitária como parte da vida pública, Gua¿. raci prestou inúmeras consultorias institucio^ nais, e, junto com outros colegas, participou de \& vários estudos sobre os processos de moderniసิ zação na Bahia, como a criação do Centro In-

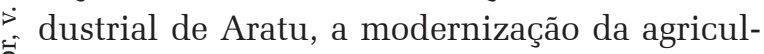
tura baiana - PDRI, Bacia do Paraguaçu, entre outros estudos socioeconômicos regionais e de impacto ambiental, além da oferta de cursos de curta duração para o planejamento governamental, guardando a necessária autonomia do trabalho acadêmico.
Com essas preocupações, liderou, no inicio da década de 80 , um processo de formulação das linhas de pesquisa do CRH (1981) e do modo de atuação do centro de pesquisas, sustentado prioritariamente por instituições de fomento, como FINEP e CNPq, de forma a ganhar maior autonomia, organizar o trabalho conjunto e evitar a dispersão de demandas nem sempre associadas aos interesses da equipe. Nessa linha de preocupações, bem mais tarde, quando do seu retorno de breve afastamento para exercer a função de assessora da graduação (1998-2002), na gestão do Reitor Heonir Rocha, implementou o Laboratório de Estudos Sociodemográficos (LAS), no CRH, apoiado pelo CTINFRA - UFBA, subprojeto 20 (Projeto FINEP n. ${ }^{\circ}$ 0959/0196015), dando prosseguimento a essa mesma linha de preocupação.

O projeto do Laboratório, do qual participei diretamente da concepção, teve por base trabalhos anteriores de Guaraci. Os objetivos principais do LAS eram viabilizar algumas das funções básicas do ensino complementar, na oferta de atividades da pesquisa básica e aplicada e da extensão universitária, como: a elaboração de pequenas análises quantitativas e qualitativas e a constituição e alimentação de bancos de dados, permitindo que essas atividades se constituíssem, ao mesmo tempo, em base para a capacitação de estudantes de graduação e pós-graduação, e para a formação especializada a jovens profissionais e gestores públicos, pela via de estágios e cursos de curta duração nos campos de interesse de pesquisa institucional do Centro.

Durante toda sua vida na UFBA, Guaraci teve um vivo engajamento institucional em defesa do Centro, cuja direção assumiu por duas vezes, entre 1972-1974 e 1992-1994, e exerceu a função de vice-diretora entre 1975-1980. Lutou pela transformação do programa em órgão suplementar da Faculdade de Filosofia e Ciências Humanas, objetivo alcançado em 1973, que perdurou até 2009, quando passou a órgão complementar. Buscou soluções para a fixação de pesquisadores contratados por convênios, na perspectiva de criar uma equipe permanente que desse sustentação às pesquisas do Centro, sem a dependência de convênios. Es- 
timulou o acesso de alguns pesquisadores a bolsas resultantes de concursos da Fundação Ford e ABEP. Conseguiu um espaço para sediar as atividades de pesquisa do $\mathrm{CRH}$, no antigo Instituto de Matemática da UFBA, criando a infraestrutura básica para o desenvolvimento das atividades das diversas equipes de pesquisa. A partir de doações de órgãos nacionais e internacionais especializados em população, constituiu um acervo documental em estudos demográficos, que foi gradativamente alimentado por intercâmbios do Caderno CRH com outros periódicos e por outras iniciativas de pesquisadores e convênios em outras temáticas das ciências sociais.

Aposentou-se em 2006, mas continuou a colaborar na condição de Professora Participante Especial da UFBA, apoiada pelo PROPAP (Programa Especial de Participação de Professores Aposentados), desenvolvendo atividades no CRH e no Programa de Pós-Graduação em Ciências Sociais - PPGCS da Faculdade de Filosofia e Ciências Humanas dessa Universidade, na oferta de cursos de metodologia e orientação de pesquisa, mas, especialmente, como membro do Conselho de Redação do $\mathrm{Ca}$ derno CRH.

Sua última produção acadêmica foi a redação do verbete "Solidariedade Familiar", para o Dicionário Temático Desenvolvimento e Questão Social (S. Paulo: Annablume, 2013, p. 481-487), que reúne a contribuição de diversos pesquisadores do CRH/UFBA, de diferentes gerações, além de muitos autores convidados, em diálogos com as tendências do desenvolvimento hoje, na sua dimensão social. Para mim, era imperativo contar com a colaboração de Guaraci nessa obra, uma das autoras precursoras dos estudos sobre o desenvolvimento no Centro, como também de outros convidados. Valeu esperar. Guaraci agradeceu muito a insistência do convite e devolveu com o sentido mais elevado da tradição maussiana da dádiva, na vida acadêmica, dedicando-se a colabo- rar com alegria e disposição na divulgação da obra. Obrigada, Guara, pela sua generosidade. Guaraci tinha consciência da importância dessa troca e sempre soube aproveitar todas as oportunidades na sua vida institucional, acadêmica e pessoal, reconvertendo-as em possibilidades de avanço, recriação e crescimento. Com grande resiliência, toda dificuldade institucional ou pessoal transformava em resistência e luta, reconstruindo possibilidades de seguir em frente ou desistir. A coerência do seu trabalho se confundia com o seu modo de ser como pessoa, pesquisadora e autora, exuberante com a vida, aproveitando cada oportunidade, cada sabor, cada descoberta, cada nexo estabelecido num autoconhecimento. A cada experiência, mobilizava sua capacidade reflexiva, dando estatuto quase teórico às vivências mais espontâneas e naturais do cotidiano, como o ofício de ser avó. Mais recentemente interessava-se pelos avanços na educação infantil e encantava-se com os aprendizados de TonTon, o seu neto. Com ele reaprendia e renovava o ciclo da vida, na sucessão das gerações! Com humor e ironia, na juventude, dizia a todos, especialmente a alguns que não compartilhavam de suas ideias, que só sairia da Universidade velhinha e de bengala na mão. Foi exatamente equilibrando-se numa bengala, mas com a firmeza de quem é dona do próprio caminho, que, nos últimos dois anos, definiu $o$ que queria e podia fazer. Transformou as ameaças à sua saúde em novo desafio de resistência e luta pela vida, e, com a sabedoria e integridade de quem não se deixa derrubar, restringiu a sua participação institucional a membro do Conselho de Redação do Caderno CRH, posição que ela distinguia com orgulho e que nos honrava com a sua presença, emprestando a esse periódico a dignidade do seu nome.

Tomo a liberdade, em nome de toda a equipe do CRH, de reafirmar, mais uma vez, obrigada, Guara! 


\section{ENTUSIASMO E CONSTÂNCIA: para lembrar Guaraci}

A professora e pesquisadora Guaraci Adeodato Alves de Souza faleceu em dezembro, mais de quarenta anos depois de ter um papel crucial na constituição do CRH/UFBA como centro de pesquisa, e vinte anos depois de concluir o último dos seus dois mandatos como Diretora desse Centro. Tanto na memória dos colegas mais antigos, estudantes e servidores que testemunharam o cumprimento desses mandatos, como na dos que conviveram com Guaraci em algum momento das duas últimas décadas, fixou-se o perfil exemplar de uma liderança cuja efetividade dispensava o exercício de cargos de direção ou coordenação. Investida ou não dessas posições, a presença de Guaraci - sua simples existência - sempre nos orientou, dirigiu, norteou. Sua palavra e seus gestos largos seguiam tendo, a cada intervenção sua, a mesma força moral que a da reputação que conquistou em sua trajetória intelectual e institucional anterior. Reputação cuja personalíssima marca inscreve-se na história oral e documentada, do CRH.

Pessoa dotada de um mister que irradiava excelência e de um senso de proporções que lhe garantia prudência, fez-se, antes de tudo, simpática amiga a quem abraçasse projetos fundados em causas de boa fé. Como se cada iniciativa precisasse de seu apoio para adquirir dignidade, e nenhum ato se tornasse pleno e justo sem antes passar pelo crivo da sua crítica. Daí nos sentirmos saudosos e contemplados diante $\rightarrow$ do legado de Guaraci. Ao lado da tristeza pela 亏ั perda de sua companhia, reluz a gratidão pelo ब apoio entusiasmado e pela crítica lúcida, corajosa e leal com que sempre agraciou seus pares. nós, seus colegas de trabalho, as lições são muitas e imensas, o que dizer do que Guaraci agregou ¿ ao patrimônio institucional de que somos parte? i Tentando resumir, num exemplo emblemático, as a quatro décadas em que ela se doou ao CRH com o esmero de quem dá à luz uma obra prima, vale pontuar a sua atuação decisiva na defesa do órgão quando, entre 2008 e 2009, ele teve sua trajetória ameaçada por uma alteração na forma do vínculo institucional com a UFBA.

O balanço criterioso e ponderado das perdas sofridas naquele processo, face ao ganho principal, que foi a preservação da trajetória institucional do Centro, não vem ao caso aqui. Vale, sim, é ressaltar a atuação interna e externa de Guaraci, crucial (como no empreendimento constituinte) para fazer o CRH reagir, resistir e se reinventar. Foi dela o gesto inicial de alertar, com assombrosa acuidade, a Direção e o Conselho Técnico do Centro para a gravidade da operação em curso, que atingiria não apenas o CRH, mas o conjunto dos então órgãos suplementares da UFBA. Assim como partiu dela a cobrança de um planejamento coletivo "realista, articulado e ágil", para enfrentar aquela conjuntura. Crítica, segundo suas próprias palavras, da "aplicação de soluções ad hoc, sem regras explícitas", não se contentava com reações casuísticas, soluções individualizadas que tentassem preservar o CRH sem discutir seu melhor modo de inserção contributiva na FFCH e na UFBA. Por outro lado, professava um otimismo de vontade sem prejuízo da lucidez, ao declarar sua convicção de que um "esforço inteligente, dedicado e correto pode, em resultado, nos levar a um novo momento bem mais rico na vida do CRH, com uma articulação mais consistente com os setores mais significativos da FFCH. Meu desejo e esforço de pensamento positivo vão por aí".

Aquele foi, talvez, o último grande embate em que sua saúde permitiu que se engajasse sem ter de dosar energias. Claro que o vigor e a abrangência das palavras de Guaraci transcendem, em muito, os limites daquele episódio e mesmo da instituição à qual ela dedicou o melhor de sua capacidade profissional e intelectual. São inspirações para posturas políticas que hão de se fazer necessárias sempre, em muitos outros processos que envolvam diferentes causas e atores. Mas o sentido autodeclarado do seu desejo e esforço, naquele processo, ecoa também como um alerta específico a todos nós, atuais pesquisadores, estudantes e servidores do CRH. É que, ao lado do seu legado pessoal, a memória permanente de Guaraci Adeodato nos lembrará de um desafio institucional que prossegue e precisa ser aceito com entusiasmo e constância, dois traços que marcavam a articulação coerente entre sua atitude e seu pensamento. Essa lição de práxis foi, pela força do exemplo, a maior que recebemos da nossa querida Guara.

(Centro de Estudos e Pesquisas em Humanidades - CRH) 


\section{Nota da Associação Brasileira de Estudos Populacionais - ABEP}

A ABEP tem o triste dever de anunciar a morte de uma de suas mais ilustres e antigas sócias - Guaraci Adeodato Alves de Souza, - Guara, para os que a conheceram - ocorrido hoje, dia 9 de dezembro. O velório acontece a partir das 16 horas e a cremação será, amanhã, às 10 horas, no Jardim da Saudade, em Salvador.

Graduada em Serviço Social, em 1965, a aproximação de Guaraci da Demografia começou logo a seguir, no curso de especialização Formation en Développement que realizou no Institut international de Recherche et de Formation en vue du Développement Harmonisé (IRFED) em Paris em 1967 -1968. De volta ao Brasil, em 1969, cursou a Especialização em Dinâmica Populacional, oferecida na Faculdade de Higiene e Saúde Pública da Universidade de São Paulo - primeiro embrião paulista na formação de demógrafos brasileiros - e, em seguida, cursou a especialização em Demografia oferecida pelo Centro Latino-americano de População na PUC-Rio. Seu Mestrado em Economia, em 1976, com a dissertação "Migração e Subemprego em Salvador" já revela sua decidida opção pela Demografia, como área preferencial de estudos.

Teórica extremamente séria e ambiciosa, embora não canônica, seu doutorado: "Sucessão das Gerações na Bahia: Reencontro de uma Totalidade Esquecida", sob a orientação de Maria Coleta Oliveira é um repto teórico extremamente complexo, parte de sua preocupação fundamental com a "busca de uma formulação teórica sobre a reprodução demográfica que desse conta, de uma maneira adequada, das interpretação desse processo enquanto processo social e histórico, tanto nos seus movimentos sincrônicos, quanto diacrônicos [e que] no plano empírico, [preocupa-se,] sobretudo,[ em] reconstruir as experiências históricas de mudança na fecundidade e nos padrões de procriação, associadas a alterações estruturais em outras dimensões da sucessão das gerações." Pelo menos um de seus trabalhos desta perspectiva foi publicado na REBEP.

Por sua preocupação teórico-política e por sua responsabilidade social, Guaraci teve enorme e importante participação no desenvolvimento da Demografia no Brasil. De diferentes formas, participou da ABEP em distintas situações: como membro da Diretoria, foi $2^{\circ}$ Presidente entre 1985 e 1986; foi membro do Conselho Consultivo na gestão 2001-2002, e ainda participou da Comissão Avaliadora de Posters em 2008. Mas seu maior trabalho foi a constituição da área de Demografia na Bahia, por uma série de ações extremamente positivas.

Em primeiro lugar, é importante ressaltar que, graças a seus esforços, foi possível a inclusão da Demografia como disciplina no Programa de Pós-Graduação em Ciências Sociais da UFBa, tendo-a como docente responsável.

Em segundo lugar, cabe enfatizar a introdução do questionamento demográfico como linha de pesquisa do CRH - Centro de Recursos Humanos - e, mais ainda, a constituição, neste centro, do Laboratório de Análises Sociodemográficas do qual foi coordenadora até recentemente. O laboratório funcionou também como posição estratégica para que Guara pudesse realizar diversas atividades de extensão, como cursos, seminários e reuniões, para os quais contou com o apoio da ABEP, do CEDEPLAR e do NEPO. Todas estas inovações tornaram-se o núcleo de desenvolvimento de uma área de estudos de Demografia na Bahia, até então inexistente.

Mas suas atividades não eram puramente acadêmicas. Polemista por natureza e por tradição familiar, Guara, antineomalthusiana ferrenha, celebrizou-se por suas discussões na imprensa, falada e escrita, com o médico baiano Elsimar Coutinho. Nestes debates, defendia o princípio da liberdade do casal no planejamento familiar, do direito ao desejo pelos filhos e pela quantidade deles, e do planejamento subordinado a este desejo e não a influências outras, tais como o Estado ou grupos sociais. Ao mesmo tempo, questionava os impactos macroestruturais de uma queda orquestrada da fecundidade que não levasse em conta a realidade do país assim como o desejo dos casais e das pessoas.

Com um feeling político extremamente aguçado, Guara ainda brigava pela Demografia em outro front: o das políticas públicas. E foi essa a razão de sua colaboração intensa com a SEI-SEPLAN do Estado da Bahia, onde atuavam e atuam vários de seus ex-alunos, que ocasionou a produção de uma série de análises sobre as mudanças sociodemográficas recentes, na Bahia e em distintas Regiões Econômi- 
cas da Bahia, inclusive nos seus diferentes municípios. Esta parceria produziu uma série de livros e deixou, como sub-produtos, bancos de dados com informações demográficas básicas, indispensáveis ao planejamento.

Enfim, resumindo, Guaraci Adeodato Alves de Souza foi uma das pioneiras que tornou possível a constituição da Demografia como área disciplinar em nosso país. Apaixonada, irreverente, engraçada, bem humorada, séria, polêmica, extremamente responsável, politicamente engajada, "porreta", Guara não vai deixar apenas saudades. Vai deixar um imenso vazio tanto na ABEP quanto em nossos corações.

(Elisabete Dória Bilac - Vice-Presidente)

(Guaraci é a representação do Sol na mitologia tupi-guarani) 